\title{
Transfection of chondromodulin I into human breast cancer cells and its effect on the inhibition of cancer cell growth
}

\author{
$\mathrm{JIE} \mathrm{SHAO}^{1^{*}}$, LINGHONG GAN $^{2 *}$ and $\mathrm{JIE} \mathrm{WANG}^{1 *}$ \\ Departments of ${ }^{1}$ General Surgery and ${ }^{2}$ Nursing, Huashan Hospital, Fudan University, Shanghai 200040, P.R. China
}

Received April 3, 2015; Accepted February 15, 2016

DOI: $10.3892 / \mathrm{mmr} .2016 .5079$

\begin{abstract}
Breast cancer affects one in every eight women, and has been associated with higher rates of female mortality than any other cancer type, with the exception of lung cancer. It has been reported that chondromodulin I (ChM-I) was able to suppress tumor angiogenesis and growth in vivo. In order to investigate the antitumor action of ChM-I on human breast cancer cells, a plasmid expressing ChM-I was constructed and transfected into human breast cancer cells using an adenoviral vector. Reverse transcription-polymerase chain reaction detected ChM-I expression in human breast cancer cell lines, whereas no expression was detected in the control groups. In order to assess the effect of ChM-I on human breast cancer cells, cell counting kit-8 (CCK-8) and colony formation analyses were used to detect tumor cell proliferation, and the proliferation of ChM-I-transfected cells was significantly reduced, as compared with the control. In addition, the mRNA expression levels of cell cycle-associated genes in ChM-I-transfected cells were significantly decreased, as compared with the control, which suggested that ChM-I transfection was able to inhibit the expression of genes associated with the cell cycle. The results of the present study indicated that ChM-I was able to inhibit the growth of breast cancer cells; thus suggesting that ChM-I may have potential clinical applications in the treatment of breast cancer.
\end{abstract}

\section{Introduction}

Breast cancer develops from the breast tissue. The most common type of breast cancer is ductal carcinoma, which begins in the lining of the milk ducts, while another type of breast cancer is lobular carcinoma, which begins in the lobules of the

Correspondence to: Professor Jie Wang, Department of General Surgery, Huashan Hospital, Fudan University, 12 Central Wulumuqi Road, Shanghai 200040, P.R. China

E-mail: prowangjie@126.com

*Contributed equally

Key words: chondromodulin-I, human breast cancer cell, proliferation, tumor, vascularization breast (1-3). Breast cancer accounts for $>10 \%$ of cancer among women worldwide, and it is the leading cause of cancer-associated mortality in women aged $20-49$ years $(3,4)$. Breast cancer incidence is increasing worldwide; in the USA, 14,000 women under the age of 40 are diagnosed with breast cancer annually and there are $\sim 3,000$ mortalities (5). Breast cancer risk factors are complex and are likely to be associated with multiple factors, including gender, age, genetics, family history of breast cancer, personal history of breast cancer, race and ethnicity (6).

Angiogenesis is essential in breast cancer progression and dissemination, and tumors have a limited ability to grow without blood supply $(7,8)$. Therefore, inhibition of the formation of blood vasculature is an effective way to stop or slow the growth of a cancer mass. Accordingly, numerous angiogenesis inhibitors have been investigated for use in the treatment of cancer. Chondromodulin I (ChM-I), an endogenous anti-angiogenic factor expressed in cartilage, has been reported to suppress tumorigenesis in vivo, due to its anti-vascularization effect (9).

To further investigate the anti-vascularization effect and antitumor activity of ChM-I, a recombinant ChM-I expressing adenovirus vector was constructed and transfected into a human breast cancer cell line. The stable expression of ChM-I in the human breast cancer cell line was established.

\section{Materials and methods}

Patients and ethical approval. Human articular cartilage used in the present study was obtained from the femoral condyles of patients undergoing knee joint replacement surgery at Huashan Hospital, Fudan University (Shanghai, China). All experimental procedures in the present study were approved by the Ethics Committee of the Shanghai Fudan University School of Medicine (Shanghai, China).

Cell culture. The MDA-MB-231 human breast cancer cell line and 293T cells were purchased from the Type Culture Collection of the Chinese Academy of Sciences (Shanghai, China). The cells were cultured at $37^{\circ} \mathrm{C}$ under $5 \% \mathrm{CO}_{2}$ in Dulbecco's Modified Eagle Medium (DMEM) supplemented with $10 \%$ fetal bovine serum and 1\% penicillin/streptomycin (all: Gibco; Thermo Fisher Scientific, Inc., Waltham, MA, USA). 
was established, as described previously (10). Briefly, total RNA was extracted from human articular cartilage using the RNeasy Mini kit (Qiagen, Inc., Valencia, CA, USA), and was reverse transcribed into cDNA for amplification by polymerase chain reaction (PCR). The primers used to specifically amplify the ChM-I cDNA are presented in Table I and were obtained from Thermo Fisher Scientific, Inc. The cycling conditions were as follows: $94^{\circ} \mathrm{C}$ for $3 \mathrm{~min}$, followed by 30 cycles of $94^{\circ} \mathrm{C}$ for $1 \mathrm{~min}, 60^{\circ} \mathrm{C}$ for $1 \mathrm{~min}$ and $72^{\circ} \mathrm{C}$ for $2 \mathrm{~min}$, and then a final extension step at $72^{\circ} \mathrm{C}$ for $5 \mathrm{~min}$. The PCR products were separated by $1.5 \%$ agarose gel electrophoresis and the target gene segment was retrieved and purified using the QIAquick Gel Extraction kit (cat. no. 28704; Qiagen, Inc.). The pcDNA3.1 linear plasmid (Invitrogen; Thermo Fisher Scientific, Inc.) underwent double enzyme digestion with Hind III and Not I (both from Thermo Fisher Scientific, Inc.), and the products of this reaction were connected with the ChM-I cDNA overnight at $16^{\circ} \mathrm{C}$ to produce the pcDNA3-ChM-I construct, which was then transformed into XL1-Blue competent bacteria (New England BioLabs, Inc., Ipswich, MA, USA). Positive bacterial colonies were selected for on Lysogeny broth media containing ampicillin (Sigma-Aldrich, St. Louis, MO, USA), and underwent plasmid extraction and purification using a commercially available kit (cat. no. 12123; Qiagen, Inc.). The extracted products were purified using the QIAquick PCR Purification kit (cat. no. 28104; Qiagen, Inc.), and sequenced (Invitrogen; Thermo Fisher Scientific, Inc.).

Construction of the adenovirus ChM-I vector. The recombinant adenoviral vector was constructed according to a previously described method (11). Briefly, human ChM-I cDNA was inserted into the Xho I and EcoRV restriction sites of the pAdTrack-CMV shuttle vector (Invitrogen; Thermo Fisher Scientific, Inc.), encoding green fluorescent protein (GFP). The resultant DNA was linearized by digestion with Pme I (New England BioLabs, Inc.), and subsequently cotransformed with an adenoviral backbone plasmid (pAdEasy-1; Agilent Technologies, Inc., Santa Clara, CA, USA) into E coli BJ5183 (Invitrogen; Thermo Fisher Scientific, Inc.). Recombinants were selected on media containing kanamycin (Thermo Fisher Scientific, Inc.) and confirmed by digestion with PacI.

Transfection of 293 T cells. The linearized recombinant plasmid was transfected into $293 \mathrm{~T}$ cells using Lipofectamine 2000 (Invitrogen; Thermo Fisher Scientific, Inc.). In 293T cells, recombination between the homologous regions of the linearized transfer cosmid vector and the adenovirus genome resulted in formation of the complete adenoviral recombinant containing the ChM-I cDNA.

Measurement of virus titers. 293T cells were used to measure the supernatant virus titer. The transfected 293T cells were collected and genomic DNA was extracted using the Genomic DNA Purification kit (cat. no. K0512; Thermo Fisher Scientific, Inc.). The extracted DNA was dissolved in $100 \mu 1$ Tris-ethylenediaminetetraacetic acid buffer (Thermo Fisher Scientific, Inc.) and underwent quantitative (q)PCR using the Mx3000P ${ }^{\circledR}$ QPCR system (Agilent Technologies, Inc.) to determine the number of vector copies in the genomic DNA. The qPCR reaction mixture consisted of $1 \mathrm{X}$ Excite
Table I. Primer sequences for polymerase chain reaction.

\begin{tabular}{|c|c|c|}
\hline Gene & Primer sequence $\left(5^{\prime}-3^{\prime}\right)$ & $\begin{array}{l}\text { Product } \\
\text { length }(b p)\end{array}$ \\
\hline ChM-I & $\begin{array}{l}\text { F: ATCAGCAGGAAGGGGAAAGC } \\
\text { R: TGGTCCCATCAGCATCAACC }\end{array}$ & 308 \\
\hline Cyclin D1 & $\begin{array}{l}\text { F: GGCGGAGGAGAACAAACAGA } \\
\text { R: TGTGAGGCGGTAGTAGGACA }\end{array}$ & 181 \\
\hline Cyclin D3 & $\begin{array}{l}\text { F: ATGGAGCTGCTGTGTTG } \\
\text { R: GAGAGGAGCCATCTAGACTA }\end{array}$ & 128 \\
\hline CDK6 & $\begin{array}{l}\text { F: TTCCCAGGCAGGCTTTTCAT } \\
\text { R: GAAAGTTGGGCAGGCTGTAT }\end{array}$ & 245 \\
\hline$\beta$-actin & $\begin{array}{l}\text { F: TCCATCATGAAGTGTGACGT } \\
\text { R: CTCAGGAGGAGCAATGATCT }\end{array}$ & 161 \\
\hline
\end{tabular}

ChM-I, chondromodulin I; CKD6, cyclin-dependent kinase 6.

Real Time Mastermix with SYBR Green (cat. no. 95088-050; BioGene, Cambridge, UK), $40 \mathrm{nM}$ each of ChM-I-specific sense and antisense primers (Table I), $1.6 \mu 1$ genomic DNA (or distilled $\mathrm{H}_{2} \mathrm{O}$ for the control), and $\mathrm{H}_{2} \mathrm{O}$ to a final volume of $20 \mu \mathrm{l}$. The thermal cycler conditions included incubation at $95^{\circ} \mathrm{C}$ for $10 \mathrm{~min}$, followed by 50 cycles of $95^{\circ} \mathrm{C}$ for $30 \mathrm{sec}$ and $59^{\circ} \mathrm{C}$ for $1 \mathrm{~min}$. Integration of the fluorescent SYBR green into the PCR product was monitored after each annealing step. Amplification of one specific product was confirmed by melting curve analysis, where a single melting peak eliminated the possibility of primer-dimer association. For melting curve analysis to be performed, the products were heated from 55 to $95^{\circ} \mathrm{C}$ after the 50 cycles.

Titers were calculated (IU/ml) according to the following formula: $\mathrm{IU} / \mathrm{ml}=(\mathrm{C} \times \mathrm{N} \times \mathrm{D} \times 1,000) / \mathrm{V}$, where $\mathrm{C}=$ proviral copies per genome, $\mathrm{N}=$ number of cells at time of transduction, $\mathrm{D}=$ dilution of vector preparation and $\mathrm{V}=$ volume of diluted vector added in each well for transduction. To obtain an accurate titer, average values were obtained from three of the vector dilutions (12).

Transfection of the ChM-I recombinant adenovirus into MDA-MB-231 human breast cancer cells. MDA-MB-231 human breast cancer cells $\left(5 \times 10^{4} / \mathrm{ml}\right)$ in the logarithmic phase were seeded into each well of a 6-well plate and divided into three groups: i) The ChM-I group (breast cancer cells transfected with ChM-I); ii) the empty vector group (breast cancer cells transfected with empty vector); and iii) the blank group (breast cancer cells).

After $12 \mathrm{~h}$ of culture and upon reaching 30-50\% confluence, the human breast cancer cells were transfected with the ChM-I adenovirus vector. Briefly, based on the pre-established experimental multiplicity of infection (MOI), $100 \mu \mathrm{l}$ virus or empty vector per $1 \mathrm{ml}$ culture medium was added to each well. The medium was replaced with the DMEM containing $10 \%$ FBS and $1 \%$ penicillin/streptomycin after $12 \mathrm{~h}$ of culture. At 4 days following transfection, the transfection efficiency was calculated based on the number of GFP-positive cells under a fluorescent microscope (Eclipse 80i; Nikon Corporation, 


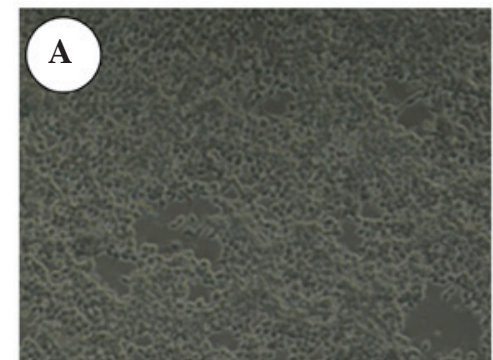

Bright field

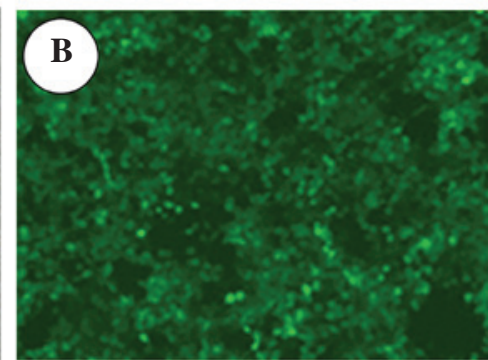

Dark field

Figure 1. Green fluorescent protein expression after transfection of Ad-chondromodulin I into 293T cells (A) Bright field. (B) Dark field (magnification, x40).

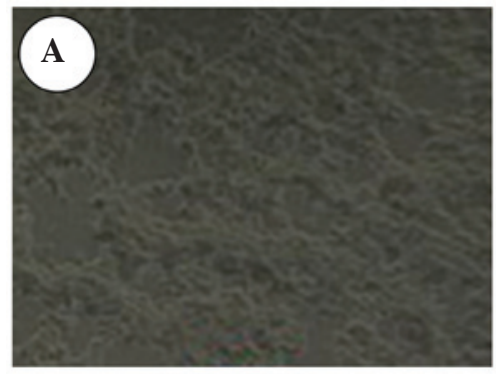

Bright field

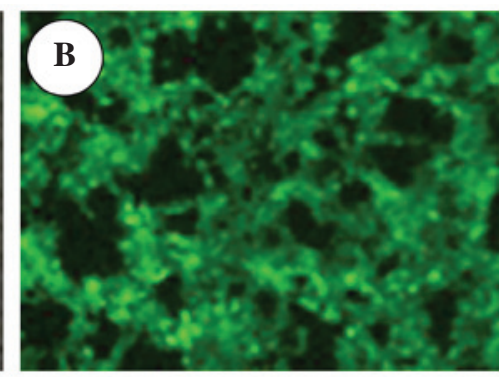

Dark field

Figure 2. Transfection of Ad-Chm-I in human breast cancer cells. Ad-ChM-I was successfully transfected and expressed in human breast cancer cells. The expression of green fluorescent protein was observed under a fluorescence microscope, and the transfection rate was $>90 \%$. (A) Bright field. (B) Dark field (magnification, x40). ChM-I:, chondromodulin I.

Tokyo, Japan). When the transfection efficiency had reached $>80 \%$, the cells were collected to assess the expression of ChM-I by reverse transcription (RT)-PCR. Briefly, total RNA was extracted from the cells using TRIzol reagent and treated with DNase (both Invitrogen; Thermo Fisher Scientific, Inc.), after which 1 mg RNA was reverse-transcribed into cDNA using a RT-PCR kit (Invitrogen; Thermo Fisher Scientific, Inc.), according to the manufacturer's protocol. The PCR cycling conditions were as follows: Amplification at $94^{\circ} \mathrm{C}$ for $4 \mathrm{~min}$, followed by 25 cycles at $60^{\circ} \mathrm{C}$ for $1 \mathrm{~min}, 72^{\circ} \mathrm{C}$ for $3 \mathrm{~min}$ and $94^{\circ} \mathrm{C}$ for $1 \mathrm{~min}$. The PCR products were resolved in a $1.5 \%$ agarose gel. The forward and reverse primers for ChM-I are presented in Table I.

Cell proliferation in vitro. Cell Counting kit-8 (CCK-8; Dojindo China Co., Ltd., Beijing, China) was used to test the cell proliferation in the ChM-I, empty vector and blank groups. In total, $10^{3}$ cells in $100 \mu 1$ medium were seeded into each well of the 96-well plate. On days 1, 3, 5 and 7, $10 \mu$ l CCK-8 solution was added to each well prior to examination. After $3 \mathrm{~h}$ of culture, the absorbance was measured spectrophotometrically at $450 \mathrm{~nm}\left(\mathrm{DU}^{\circledR}\right.$ Series 700 UV/Vis Scanning Spectrophotometer (Beckman Coulter, Inc., Brea, CA, USA). These experiments were conducted at least in triplicate.

Colony formation assays. Cells in the ChM-I, empty vector and blank cell groups were cultured on $35 \mathrm{~mm}$ culture plates as described (9). The cells were detached and suspended in culture medium containing $0.68 \%$ malting agar (Sigma-Aldrich). The cell suspension was then plated on culture medium containing $0.4 \%$ agarose that had been allowed to harden beforehand. The culture medium was changed every 2-3 days. The numbers of colonies were measured under a phase contrast microscope (Olympus CX31; Olympus Soft Imaging Solutions GmbH, Münster, Germany) on days 7, 14 and 21 of culture. The experiment was conducted in triplicate.

Analysis of the mRNA expression levels of cell-cycle associated genes in target cells. RT-qPCR was used to investigate the mRNA expression levels of genes associated with the cell-cycle. Briefly, total RNA was extracted from the human breast cancer cells using TRIzol reagent, according to the manufacturer's protocol. RNA was reverse transcribed into cDNA using the Reverse Transcription kit (Qiagen, Inc.). PCR was performed in a qPCR detection system (Bio-Rad Laboratories, Hercules, CA, USA) and conducted with iQ SYBR Green Supermix (Bio-Rad). The primer sequences are presented in Table I. The cycling conditions were as follows: One cycle at $50^{\circ} \mathrm{C}$ for $2 \mathrm{~min}$; one cycle at $95^{\circ} \mathrm{C}$ for $10 \mathrm{~min}$; 40 cycles at $95^{\circ} \mathrm{C}$ for $15 \mathrm{sec}, 60^{\circ} \mathrm{C}$ for $30 \mathrm{sec}$ and $72^{\circ} \mathrm{C}$ for $30 \mathrm{sec}$; and one cycle at $72^{\circ} \mathrm{C}$ for $10 \mathrm{~min}$. Amplification reactions were performed in duplicate and the amount of cDNA in the reactions was normalized to $\beta$-actin. The specificity of the amplification was confirmed by $2 \%$ agarose gel electrophoresis and by analysis of the melting curves. An amplification reaction control with no reverse transcriptase enzyme was performed in order to assess the interference of potential genomic DNA in the RNA solution. Relative mRNA expression levels were calculated using the $2^{-\Delta \Delta C q}$ method (13).

Statistical analysis. Data are presented as the mean \pm standard deviation. Data were analyzed using the SPSS 17.0 software 
Table II. Virus titer calculation.

\begin{tabular}{ccccccc}
\hline Sample & V & C & N & D & IU & Mean \\
\hline 1 & 10 & 261.75 & $2 \times 10^{5}$ & 1 & $5.23 \mathrm{E}+09$ & $5.19 \mathrm{E} \pm 09$ \\
2 & 1 & 20.05 & $2 \times 10^{5}$ & 1 & $4.10 \mathrm{E}+09$ & \\
3 & 0.1 & 3.12 & $2 \times 10^{5}$ & 1 & $6.24 \mathrm{E}+09$ & \\
\hline
\end{tabular}

$\mathrm{IU} / \mathrm{ml}=(\mathrm{CxNxDx} 1,000) / \mathrm{V}$, where $\mathrm{C}=$ proviral copies per genome, $\mathrm{N}=$ number of cells at time of transduction, $\mathrm{D}=$ dilution of vector preparation, $\mathrm{V}=$ volume $(\mathrm{ml})$ of diluted adenovirus sample added into each well for transduction.

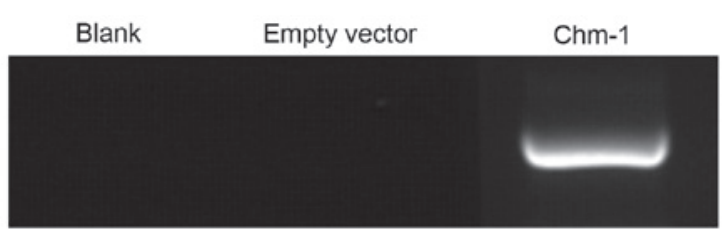

Figure 3. ChM-I expression in human breast cancer cells by RT-PCR. The production of the RT-PCR was detected by $1 \%$ agarose gel electrophoresis. ChM-I strongly expressed in the ChM-I group $(\sim 1,000 \mathrm{bp})$. RT-PCR, reverse transcription-polymerase chain reaction; ChM-I, chondromodulin I.

(SPSS Inc., Chicago, IL, USA). One-way analysis of variance followed by Fisher's Least Significant Difference test were used to assess differences among groups. $\mathrm{P}<0.05$ was considered to indicate a statistically significant difference.

\section{Results}

Transfection of the ChM-I recombinant adenovirus in $293 T$ cells. The ChM-I recombinant adenovirus was transfected into 293 T cells. Fluorescence microscopy was used to GFP fluorescence following transfection, and the transfection rate was $>95 \%$ (Fig. 1). RT-qPCR was used to determine the number of vector copies associated with genomic DNA extracted from transduced 293T cells. Vector copy numbers in 293T cells are normalized to human RNaseP gene copies and presented as proviral copies per genome equivalent. The average value obtained from 3 of the vector dilutions was $5.19 \times 10^{9} \mathrm{IU} / \mathrm{ml}$ (Table II).

Transfection of the ChM-I recombinant adenovirus in human breast cancer cells. The ChM-I recombinant adenovirus was successfully transfected and expressed constitutively in human breast cancer cells. The expression of GFP was observed in the experimental group under fluorescence microscope examination. Following recombinant adenovirus transfection for 7 days in human breast cancer cells, the transfection rate was $>90 \%$ (Fig. 2). The result of RT-qPCR showed that expression of ChM-I was observed in the ChM-I transfected cell group, while no expression was identified in the in control groups (Fig. 3).

Ad-ChM-I inhibits the growth of human breast cancer cells in vitro. Compared with the two other groups, there was a significantly decrease in the cell growth of human breast
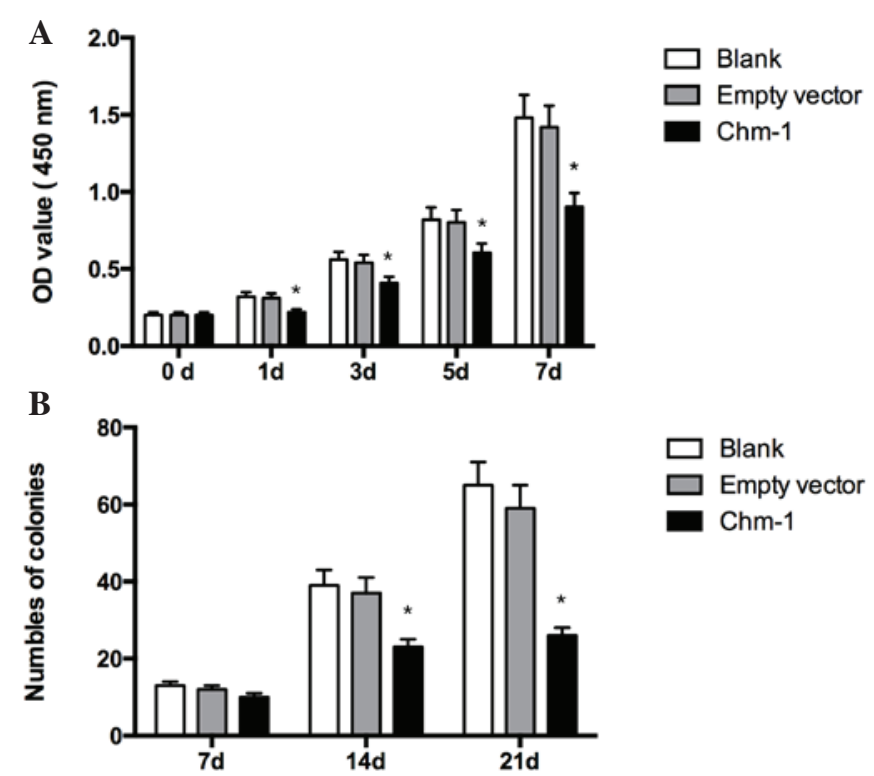

Figure 4. Growth and colony formation assay of human breast cancer cells in vitro. (A) There was a significant decrease in the cell growth of human breast cancer cells transfected with Ad-ChM-I cultures $(\mathrm{P}<0.05)$. (B) Ad-ChM-I infection suppressed the number of colonies of the human breast cancer cells. Data are presented as the mean \pm standard deviation. ${ }^{*} \mathrm{P}<0.05$ vs. the blank and empty vector groups. OD, optical density; ChM-I, chondromodulin I.

A
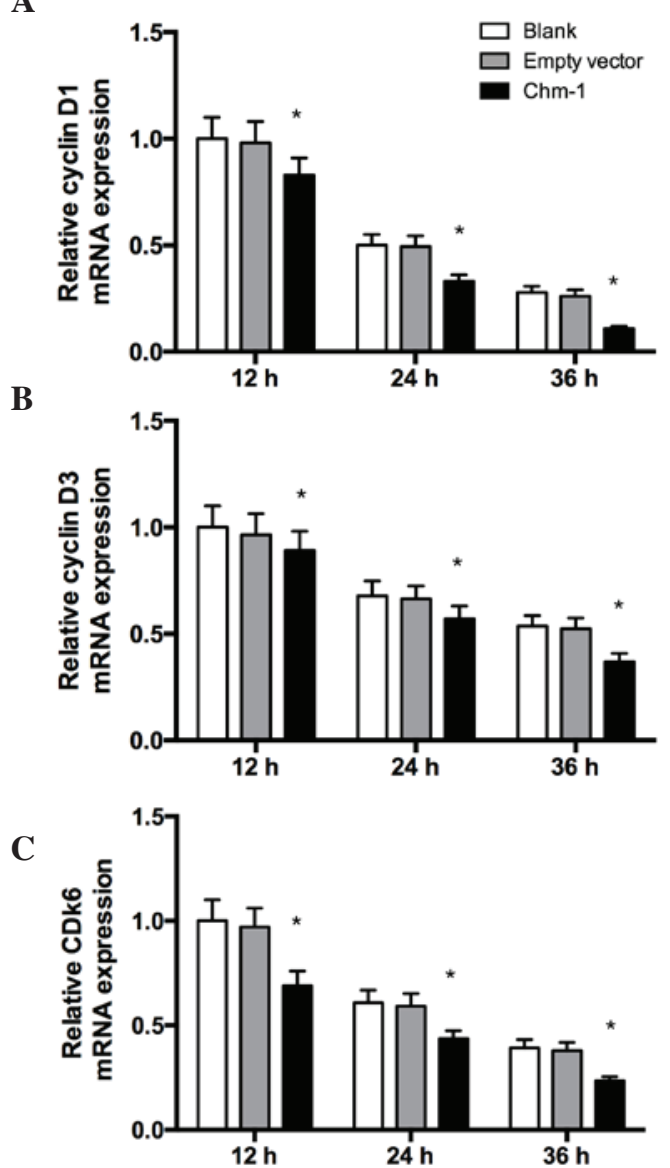

Figure 5. Results of reverse transcription-quantitative polymerase chain reaction analysis. The cells transfected with Ad-ChM-I exhibited a significant decrease in the mRNA expression of (A) cyclin D1, (B) cyclin D3 and (C) CDK6, compared with the control groups $\left({ }^{*} \mathrm{P}<0.05\right)$. No difference was identified between the levels in the blank group and the empty vector group (P>0.05). CDK6, cyclin-dependent kinase 6; ChM-I, chondromodulin I. 
cancer cell lines transfected with Ad-ChM-I cultures, indicating that ChM-I suppresses the proliferation of breast cancer cells (Fig. 4A).

Colony formation assay. A colony formation assay was conducted. Ad-ChM-I infection markedly suppressed the number of colonies of human breast cancer cells, a result that was consistent with the in vitro CCK-8 results (Fig. 4B).

ChM-I suppresses the expression of cell cycle-related genes in human breast cancer cells. To investigate the mechanism of ChM-I-induced suppression of tumor cell growth, the expression levels of cell cycle-related genes in human breast cancer cells were examined in vitro by RT-qPCR analysis. As shown in Fig. 5, Ad-ChM-I inhibited the levels of certain cell cycle-related genes after infection, the levels of cyclin D1, cyclin D3, and cyclin-dependent kinase (CDK)6 were significantly decreased by Ad-ChM-I.

\section{Discussion}

Angiogenesis is essential in tumor development and subsequent growth, invasion and metastasis (14). Tumors require a blood supply to grow and spread, and blood vessels are required for tumors to grow beyond a few millimeters in size. Tumors can secrete chemical signals that stimulate angiogenesis to form blood vessels to increase supply. In addition, tumors can also stimulate nearby normal cells to produce angiogenesis signaling molecules $(15,16)$.

Among the various angiogenic factors that are involved in tumor development, vascular endothelial growth factor (VEGF) is the most prominent $(17,18)$. Thereby VEGF has been considered as a therapeutic target, and angiogenesis inhibitors have been designed to prevent the formation of novel blood vessels, to stop or slow the growth or spread of tumors $(19,20)$. Accordingly, a variety of drugs blocking VEGF signal have been developed in recent years $(21,22)$.

ChM-I is a $25-\mathrm{kDa}$ glycoprotein, which contains two distinctive structural domains: The N-terminal third of the molecule is a hydrophilic domain that contains O-linked and $\mathrm{N}$-linked oligosaccharide chains, and the $\mathrm{C}$-terminal two-thirds is a hydrophobic domain that contains all of the cysteine residues, and is considered as an effective anti-vascualarization factor (23). Hakuno et al (24) reported that ChM-I is a crucial factor for maintaining normal cardiac valvular function by preventing angiogenesis that may lead to valvular heart diseases. Klinger et al (25) showed that CmH-I stabilizes the chondrocyte phenotype and inhibits endochondral ossification of porcine cartilage repair tissue. Mera et al (9) reported that ChM-I directly suppresses the proliferation of tumor cells in an anchorage-independent manner. In addition, Hiraki et al (26) reported that ChM-I was identified as an angiogenesis inhibitor, and found that ChM-I is specifically expressed in the avascular zone of cartilage in developing bone, but not present in calcifying cartilage. Purified ChM-I inhibited DNA synthesis and proliferation of vascular endothelial cells as well as tube morphogenesis in vitro (26).

The central importance of tumor neovascularization has been emphasized by experimental and clinical trials in various tumor types $(27,28)$, and ChM-I has been shown to exhibit anti-vascularization action, thus, the present study aimed to transfect ChM-I into human breast cancer cells in order to investigate the effects of ChM-I.

In the present study, an adenoviral vector expressing ChM-I was constructed. Use of adenoviral vectors offers multiple advantages for gene replacement therapy, as they combine efficient delivery, an ability to transduce proliferating and non-proliferating cells, a capacity to integrate into the host chromatin to provide stable long-term expression of the transgene, an absence of any viral genes in the vector and an absence of interference from preexisting viral immunity (29). In the present study, ChM-I was successfully transfected into breast cancer cells and stably expressed. The effect of ChM-I on the proliferation on breast cancer cells was analyzed using CCK-8 and colony forming assays. It was demonstrated that ChM-I had a significant inhibitory effect on breast cancer cell proliferation. It is has previously been shown that cyclin D1, cyclin D3 and CDK6 are able to promote cell division, therefore, the expression of these genes was analyzed following ChM-I transfection. Ad-ChM-I significantly decreased the mRNA expression levels of cyclin D1, cyclin D3 and CDK6. These results suggested that ChM-I had a significant inhibitory effect on breast cancer cell division and proliferation.

In conclusion, recombinant ChM-I was successfully constructed and transfected into human breast cancer cells, wherein it was shown to be stably expressed. The in vitro results suggested that ChM-I was able to inhibit the growth of human breast cancer cells. Further in vivo studies are required to explore the role of ChM-I in human breast cancer cells.

\section{Acknowledgements}

This study was supported by the National Natural Science Fund of China (grant no. 81072188).

\section{References}

1. Brinton LA, Smith L, Gierach GL, Pfeiffer RM, Nyante SJ, Sherman ME, Park Y, Hollenbeck AR and Dallal CM: Breast cancer risk in older women: Results from the NIH-AARP diet and health study. Cancer Causes Control 25: 843-857, 2014.

2. National Cancer Institute: Breast cancer. In: What You Need To Know About. National Institutes of Health, Bethesda, MD, 2012.

3. Nyante SJ, Dallal CM, Gierach GL, Park Y, Hollenbeck AR and Brinton LA: Risk factors for specific histopathological types of postmenopausal breast cancer in the NIH-AARP diet and health study. Am J Epidemiol 178: 359-371, 2013.

4. Sasco AJ: Breast cancer and the environment. Horm Res 60 (Suppl 3): S50, 2003.

5. Ruddy KJ, Greaney ML, Sprunck-Harrild K, Meyer ME, Emmons KM and Partridge AH: Young women with breast cancer: A focus group study of unmet needs. J Adolesc Young Adult Oncol 2: 153-160, 2013.

6. John EM, Hopper JL, Beck JC, Knight JA, Neuhausen SL, Senie RT, Ziogas A, Andrulis IL, Anton-Culver H, Boyd N, et al: The breast cancer family registry: An infrastructure for cooperative multinational, interdisciplinary and translational studies of the genetic epidemiology of breast cancer. Breast Cancer Res 6: R375-R389, 2004.

7. Fantozzi A and Christofori G: Mouse models of breast cancer metastasis. Breast Cancer Res 8: 212, 2006.

8. Zetter BR: Angiogenesis and tumor metastasis. Annu Rev Med 49: 407-424, 1998

9. Mera H, Kawashima H, Yoshizawa T, Ishibashi O, Ali MM, Hayami T, Kitahara H, Yamagiwa H, Kondo N, Ogose A, et al: Chondromodulin-1 directly suppresses growth of human cancer cells. BMC Cancer 9: 166, 2009. 
10. Xing S, Wang Z, Xi H, Zhou L, Wang D, Sang L, Wang X, Qi M and Zhai L: Establishment of rat bone mesenchymal stem cell lines stably expressing Chondromodulin I. Int J Clin Exp Med 5: 34-43, 2012

11. Lin L, Fu X, Zhang X, Chen LX, Zhang JY, Yu CL, Ma KT and Zhou CY: Rat adipose-derived stromal cells expressing BMP4 induce ectopic bone formation in vitro and in vivo. Acta Pharmacol Sin 27: 1608-1615, 2006

12. Wang S, Zeng X, Liu Y, Liang C, Zhang H, Liu C, Du W and Zhang Z: Construction and characterization of a PDCD5 recombinant lentivirus vector and its expression in tumor cells. Oncol Rep 28: 91-98, 2012.

13. Livak KJ and Schmittgen TD: Analysis of relative gene expression data using real-time quantitative PCR and the 2(-Delta Delta C(T)) Method. Methods 25: 402-408, 2001.

14. Zheng K, Li HY, Su XL, Wang XY, Tian T, Li F and Ren GS: Chemokine receptor CXCR7 regulates the invasion, angiogenesis and tumor growth of human hepatocellular carcinoma cells. J Exp Clin Cancer Res 29: 31, 2010.

15. Nishida N, Yano H, Nishida T, Kamura $T$ and Kojiro $M$ : Angiogenesis in cancer. Vasc Health Risk Manag 2: 213-219, 2006

16. Wels J, Kaplan RN, Rafii S and Lyden D: Migratory neighbors and distant invaders: Tumor-associated niche cells. Genes Dev 22: 559-574, 2008

17. Hoeben A, Landuyt B, Highley MS, Wildiers H, Van Oosterom AT and De Bruijn EA: Vascular endothelial growth factor and angiogenesis. Pharmacol Rev 56: 549-580, 2004.

18. Neufeld G, Cohen T, Gengrinovitch S and Poltorak Z: Vascular endothelial growth factor (VEGF) and its receptors. FASEB J 13: 9-22, 1999 .

19. Ferrara N: Vascular endothelial growth factor as a target for anticancer therapy. Oncologist 9 (Suppl 1): S2-S10, 2004.
20. Ferrara N: VEGF as a therapeutic target in cancer. Oncology 69 (Suppl 3): S11-S16, 2005.

21. Shibuya M: VEGF-VEGFR signals in health and disease. Biomol Ther (Seoul) 22: 1-9, 2014.

22. Ma J and Waxman DJ: Combination of antiangiogenesis with chemotherapy for more effective cancer treatment. Mol Cancer Ther 7: 3670-3684, 2008.

23. Miura S, Kondo J, Kawakami T, Shukunami C, Aimoto S, Tanaka $\mathrm{H}$ and Hiraki Y: Synthetic disulfide-bridged cyclic peptides mimic the anti-angiogenic actions of chondromodulin-I. Cancer Sci 103: 1311-1318, 2012.

24. Hakuno D and Fukuda K: Role of anti-angiogenic factor chondromodulin-I for maintaining cardiac valvular function. Clin Calcium 17: 361-372, 2007 (In Japanese).

25. Klinger P, Surmann-Schmitt C, Brem M, Swoboda B Distler JH, Carl HD, von der Mark K, Hennig FF and Gelse K: Chondromodulin 1 stabilizes the chondrocyte phenotype and inhibits endochondral ossification of porcine cartilage repair tissue. Arthritis Rheum 63: 2721-2731, 2011.

26. Hiraki $Y$, Inoue $H$, Iyama K, Kamizono A, Ochiai M, Shukunami C, Iijima S, Suzuki F and Kondo J: Identification of chondromodulin I as a novel endothelial cell growth inhibitor. Purification and its localization in the avascular zone of epiphyseal cartilage. J Biol Chem 272: 32419-32426, 1997.

27. Fox SB, Generali DG and Harris AL: Breast tumour angiogenesis. Breast Cancer Res 9: 216, 2007.

28. Miller KD: Recent translational research: Antiangiogenic therapy for breast cancer - where do we stand? Breast Cancer Res 6: 128-132, 2004.

29. Muruve DA: The innate immune response to adenovirus vectors. Human Gene Ther 15: 1157-1166, 2004. 